\title{
Role of Ultrasound in Evaluation of Developmental Dysplasia of the Hip in Infants
}

\author{
Ali Hassan A. Ali1, ${ }^{1 *}$, Jamaan Al-Zahrani ${ }^{3}$, Abbas Elbakry A. Elsayed ${ }^{4,5}$, Omar O. Serhan6 $^{6}$ \\ ${ }^{1}$ Anatomy Department, College of Medicine, Prince Sattam Bin Abdulaziz University, Al-Kharj, KSA \\ ${ }^{2}$ Anatomy Department, Faculty of Medicine, Al-Azhar University, Cairo, Egypt \\ ${ }^{3}$ Department of Family Medicine, College of Medicine, Prince Sattam Bin Abdulaziz University, Al-Kharj, KSA \\ ${ }^{4}$ Pediatric Department, College of Medicine, Prince Sattam Bin Abdulaziz University, Al-Kharj, KSA \\ ${ }^{5}$ Pediatric Department, Faculty of Medicine, Al-Azhar University, Assuit, Egypt \\ ${ }^{6}$ Radiology Department, King Khalid Hospital, Al-Kharj, KSA \\ Email:*alihassan3750@yahoo.com
}

How to cite this paper: Ali, A.H.A., AlZahrani, J., Elsayed, A.E.A. and Serhan, O.O. (2017) Role of Ultrasound in Evaluation of Developmental Dysplasia of the Hip in Infants. Open Journal of Pediatrics, 7, 1-12. https://doi.org/10.4236/ojped.2017.71001

Received: December 19, 2016

Accepted: February 7, 2017

Published: February 10, 2017

Copyright $\odot 2017$ by authors and Scientific Research Publishing Inc. This work is licensed under the Creative Commons Attribution International License (CC BY 4.0).

http://creativecommons.org/licenses/by/4.0/

\begin{abstract}
Background/Aim: The present study was directed to investigate the accuracy of ultrasound (USG) in early detection of developmental dysplasia of the hip (DDH) to prevent permanent complications. Material \& Methods: A total of 276 infants was investigated; their ages range from $1-6$ months. Patients referred from the clinic based on clinical assessment (mainly Barlo \& Ortolani maneuvers). Then the patient's hips were examined by expert radiologists in USG scan. After that, dynamic (coronal and transverse) \& static ultrasound views evaluated by the same radiologist using Graf's criteria. Infants with abnormal ultrasound findings suggestive of DDH were followed up after 4 - 6 weeks by the same investigator to monitor the progress. At the same time, the patient referred to a specialist for conservative management from the first positive findings. Results: Among the 276 referred patients, infants with normal stable hips (Graf Type I and Type II a+) were 221 (80\%), 155 of them were female and 66 male infants. Infants with unstable hips based on Graf's criteria (Type II a-, II b, II c and Type III a) were 55 (20\%). Out of 55 with abnormal findings, the affected hips on both sides, right and left were: 5 cases $(1.8 \%), 7$ $(2.5 \%)$ and 43 hips (15.5\%) consecutively. Out of 55 infants affected; 3 referred to tertiary centers for further surgical management while 52 managed conservatively. Conclusion: Delayed treatment rates of DDH and complications could be reduced by the usage of the USG after the first month of life. In addition to physical assessment, USG for high-risk infants will provide more accurate diagnosis and minimize complications.
\end{abstract}

\section{Keywords}

Developmental Dysplasia of the Hip, Ultrasonography, Infants, Grafs Criteria 


\section{Introduction}

In neonates, a dislocated hip may be easily reduced by simple manipulation during clinical examination, and stabilization occurs as the soft tissues tighten. An unstable or dislocatable hip may also stabilize spontaneously. When the femoral head is aligned with the center of the acetabulum, the dysplastic acetabulum often normalizes within the first months of life. If the hip remains dislocated, soft tissue contractures develop rapidly, and surgery is likely to be required to obtain and maintain joint reduction. The longer the hip is left in an abnormal position, the more the anatomy changes, developing abnormalities of both the proximal femur and the acetabulum.

Developmental dysplasia of the hip affects $1 \%-3 \%$ of all newborns; it ranges from mild acetabular dysplasia with a stable hip to a frankly dislocated hip with a dysmorphic femoral head and acetabulum.

Plain radiographs are of limited value for diagnosis in the newborn child because the femoral head and acetabulum are largely cartilaginous. Ultrasound (USG) scanning is the investigation of choice to evaluate DDH in infants younger than six months of age and is useful to diagnose more subtle forms of the disorder when the clinical exam is equivocal [1]. Because not all infants can be screened for DDH by experts, early diagnosis of developmental dysplasia of the hip (DDH) by primary health care professionals is important. An ultrasound scan is a painless test that uses sound waves to detect structures in the body. It is the same type of scan that is done routinely on pregnant women early in their pregnancy. The recommendations about the usage of USG as standard methods to diagnose early DDH remains controversial, as more evidence is needed to recommend ultrasound screening [2] [3] [4] [5] [6].

Diagnosis of DDH is crucial in the fast-growing underdeveloped communities with the tradition of swaddling. Early diagnosis of the disease relies mostly on physical examination by experienced health care professionals and ultrasound screening of the hip with proper probes. Primary care physicians working in rural places lack the knowledge of DDH examination and the availability of an experienced health care professional certified for ultrasound screening is typically unavailable [6] [7].

The origin and pathogenesis of $\mathrm{DDH}$ are multifactorial. Abnormal laxity of the ligaments and hip capsule is seen in patients with DDH. The maternal hormone relaxin may also be a factor. Causes of oligohydramnios are thought to be reduced in other, movement restriction, and being a first-born child. Extreme hip flexion with knee extension, as in the breech position, tends to promote femoral head dislocation and leads to the shortening and contracting of the iliopsoas muscle [8] [9].

Experience with ultrasonography (USG) has documented its ability to detect abnormal position, instability, and dysplasia not evident on clinical examination. Ultrasonography during the first four weeks of life often reveals the presence of minor degrees of instability and acetabular immaturity [9].

If $\mathrm{DDH}$ is not diagnosed and treated early, they may develop early arthritis of 
the hip joint. This causes pain and reduced movement. The treatment of DDH gets more complex and with less chance of success once your child's bones have fully developed. Even at this stage, though, treatment can still provide a longterm outcome which is better than the alternative of no treatment. Indeed, the duration of treatment was shorter in patients treated at an early age (45 days); surgery was not required, and in all patient ultrasound findings provided evidence of normalization of clinical parameters [10].

Tréguier et al. studied the pubofemoral distance (PFD) on 980 infants who underwent ultrasonography of the hips in comparison with the final diagnosis, based on clinical, ultrasound data and follow-up. They found PFD measurement with a threshold for abnormality of $6 \mathrm{~mm}$ at the age of 1 month, without asymmetry above $1.5 \mathrm{~mm}$, could eradicate DDH late diagnosis [11].

On the other hand, Dornacher \& colleagues study the sonographic findings of 90 children with DDH. They found no significant correlation between the Graf classification and the radiological outcome at follow-up. Even after successful ultrasound-monitored treatment, a risk for residual dysplasia remains. Therefore, radiological follow-up of every hip treated once is necessary. In addition, there is no correlation between the severity of DDH measured by ultrasound and the subsequent presence of residual dysplasia at radiological follow-up [12].

Pashapour and Golmahammadlou used Ortalani and Barlow methods and sonography for diagnosis. Of 105 suspected cases. 10 were confirmed with developmental dysplasia of the hip; 7 diagnosed during the study, and only 3 cases had been diagnosed previously. This late diagnosis is far greater than reported in other studies [13].

Clinical study of Misanovic et al. included a total of 150 participants, out of which there were 77 females and 73 were male. The manner of diagnosing suspected developmental hip dysplasia was done via clinical, ultrasound and radiological examination. In the investigated group, a positive clinical finding was established in $22.6 \%$ children while no pathological changes were found in $77.3 \%$ participants. In the control group a positive clinical finding was established in $28 \%$, and normal finding in $72 \%$ patients [14].

However, Sonographic evaluation of the hip appears to vary depending on the investigator. Ultrasonography of normal hips has low inter-observer reliability. It should be kept in mind that ultrasonographic evaluation in the follow-up and treatment of DDH may vary, depending on the practitioners [15].

Due to lack of local studies in Saudi community that support our aim to investigate the effectiveness of ultrasound in the early detection of $\mathrm{DDH}$; we would conduct this study to highlight the role of ultrasound in early diagnosis and management of DDH to prevent permanent complications.

\section{Methods}

The present study was carried out in the Radiology Department at King Khalid Hospital $(\mathrm{KKH})$ in collaboration with Anatomy and Pediatric Departments of 
Prince Sattam Bin Abdulaziz University in Al-Kharj, Kingdom of Saudi Arabia (KSA). It was a prospective study. Institutional Review Board (IRB) approval for this survey done by Reference Number (35 - 115), as well as agreement from King Khaled Hospital.

Patients enrolled were those from 1 - 6 month-old. Enrollment started by explaining the criteria to the pediatric orthopedic. The sample size based on estimated size according to litrative research with similar criteria. Any patient suspected to have DDH in the age group specified, it was refered for USG. Clinical examination and an ultrasound scan performed. Those with neuromuscular disorders, those ages $\geq$ six months or less than one month of age were excluded. Patients referred from Orthopedic clinics if they have a clinical suspicion of DDH (Barlow and Ortolani maneuvers and/or risk factors).

At radiology department; an expert radiologist examined all hip joints before the procedure (using Barlow and Ortolani) with and without stress. Then, the USG at rest and under stress were applied to assess: the hip morphology, femoral head position and hip stability by the same radiologist.

A lateral approach was used, with the infant supine or in the lateral decubitus position. The scanning is performed in the coronal plane with the hips extended or flexed. In the axial (transverse) plane the thighs are flexed at 90 degrees of flexion, and images are obtained with and without stress. The bones and cartilaginous components of the hip joint were well demonstrated on the displayed images, and acetabular coverage of the femoral head was assessed. The same steps were taken on the other side. After that, dynamic (coronal and transverse views) using hybrid exam style, either dynamic real-time scan or static analysis or both, See Graf's classification (Table 1) [9]. The same radiologist assessed ultrasound findings on dynamic-visual appreciation- and biometric based analysis, measurements are usually performed to confirm the grade of abnormality on the static image. Stress is applied to check suitability. On frozen coronal view, an imaginary line is drawn from the iliac bone baseline, extended through the femoral head, another line through the acetabular roof crosses the first one. After that, alpha and beta angles generated and intersected the apparent circle of the hypoechoic femoral head, dividing the circle into two horizontal parts; the

Table 1. Graf's classification [9].

\begin{tabular}{cl}
\hline TYPES & \multicolumn{1}{c}{ DEFINITION } \\
\hline Type I & Is a mature hip with $\alpha$ angle $>60^{\circ}$. It is divided into two subgroups: type 1a, with $\beta$ angle $>55^{\circ}$; and type $1 \mathrm{~b}$ with $\beta$ angle $<55^{\circ}$. \\
\hline Type IIa & $\begin{array}{l}\text { Is the physiologic immature hip in which } \alpha \text { is between } 50^{\circ} \text { and } 59^{\circ} \text { in an infant younger than } 12 \text { weeks of age. If type } 2 \mathrm{a} \text { morphology } \\
\text { persists beyond } 12 \text { weeks, it is termed as type } 2 \mathrm{~b} \text { (acetabular dysplasia) where } \alpha \text { is between } 50^{\circ} \text { and } 59^{\circ} .\end{array}$ \\
Type IIc $\begin{array}{l}\text { Is a hip in the critical range } \alpha=43^{\circ}-49^{\circ} \text {. It is divided into two subgroups: Type } 2 \mathrm{c} \text { stable and Type } 2 \mathrm{c} \text { unstable. } \\
\text { In the Type D hip, the } \alpha \text { angle is in the same range as in the Type } 2 \mathrm{chip} \text {; however, the Type D is decentered and has a } \beta \text { angle }>77^{\circ} .\end{array}$ \\
Hips are both decentered hips, with $\alpha<43^{\circ}$ and $\beta>77^{\circ}$ in each. \\
Determination of the position of the cartilaginous roof is crucial for the differentiation of Type 3 and 4 , which is pushed cranially in \\
Type IV $\begin{array}{l}\text { Type } 3 \text { hips, and caudally in Type } 4 \text { hips. } \\
\text { Type } 3 \text { hip is further divided into two subgroups according to the echogenicity of the cartilaginous roof. In Type } 3 \mathrm{a} \text { hips, the roof is } \\
\text { hypoechoic, whereas, in the Type } 3 \mathrm{~b} \text { hip, the hyaline cartilage is deformed, and appears hyperechoic. }\end{array}$ \\
\hline
\end{tabular}


deepest one resembles the percentage of femoral head coverage and correlates with the bone (alpha angle), the other path corresponds to none coverage and correlate with cartilage (beta angle).

As the alpha angle for a normal scan varies from more than 50 to 60 degrees visual appreciation is a sensitive method, and measurements should be reserved for dysplastic hip classification and monitoring. Positive findings on dynamic ultrasound views in addition to the visual appreciation include the following: assessment of acetabular morphology, head of femoral sphericity and roundness, and proximal capital femoral epiphyseal ossification center, as well as stability. Patients with positive ultrasound findings followed up after 4 to 6 weeks by the same investigator to monitor the progress. At the same time, the patient referred to a specialist for management from the first positive findings. Those with Graf type I hips (mature type) were excluded from follow-up. The same radiologist performed initial screening and monitoring.

The data were analyzed using SPSS 20 Software. Descriptive statistics such as means and standard deviation were used to summarize the quantitative variables. Proportion and percentages were used to summarize categorical variables. Differences were considered significant if the $\mathrm{P}$ value is $<0.05$.

\section{Results}

In total, 276 children participated in the study. The total number of hips scanned by USG were 552 (both sides, right or left). Their mean age at presentation was 3.2 months. There were 76 males and 200 females in this study. In Table 2, more than half of participants (54.3\%) demonstrated positive findings using USG in the first visit, but this number decreased after the second assessment to $18.8 \%$ (Figure 1). Most of the infants that revealed DDH features using sonogram are those aged 2 to 4 months, with decreased chance as they grow up (Table 3 and Figure 2).

Table 2. Infants with positive DDH findings by USG.

\begin{tabular}{ccccc}
\hline & \multicolumn{2}{c}{ DDH findings 1st Visit } & \multicolumn{2}{c}{ DDH findings 2nd Visit } \\
\cline { 2 - 5 } Total & Positive & Negative & Positive & Negative \\
\hline
\end{tabular}
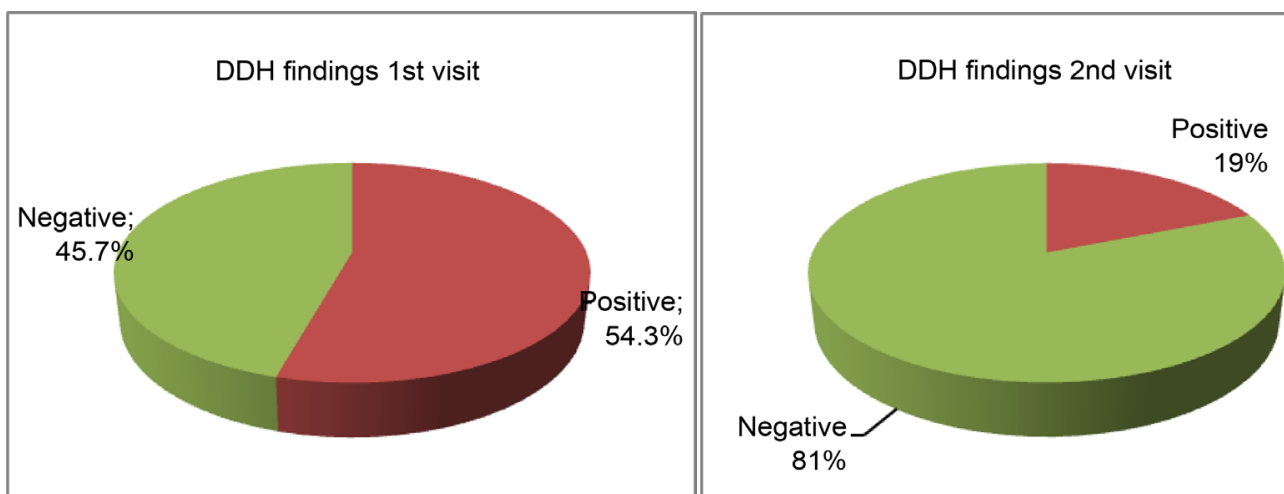

Figure 1. Infants with positive DDH by USG. 
Table 3. Infants with DDH using USG matched by age group.

\begin{tabular}{ccccc}
\hline \multirow{2}{*}{ Age Group } & \multicolumn{2}{c}{ DDH findings 1st Visit } & \multicolumn{2}{c}{ DDH findings 2nd Visit } \\
\cline { 2 - 5 } & Positive & Negative & Positive & Negative \\
\hline From 1 to 2 months & $16(5.9 \%)$ & $20(7.0 \%)$ & $6(3.2 \%)$ & $18(9.7 \%)$ \\
From 2 to 4 months & $99(36.0 \%)$ & $96(34.9 \%)$ & $19(10.2 \%)$ & $113(60.8 \%)$ \\
From 4 to 5 months & $20(7.0 \%)$ & $9(3.2 \%)$ & $6(3.2 \%)$ & $13(7.0 \%)$ \\
From 5 to 6 months & $15(5.4 \%)$ & $1(0.5 \%)$ & $4(2.2 \%)$ & $7(3.8 \%)$ \\
Total & $150(54.3 \%)$ & $126(45.7 \%)$ & $35(18.8 \%)$ & $151(81.2 \%)$
\end{tabular}

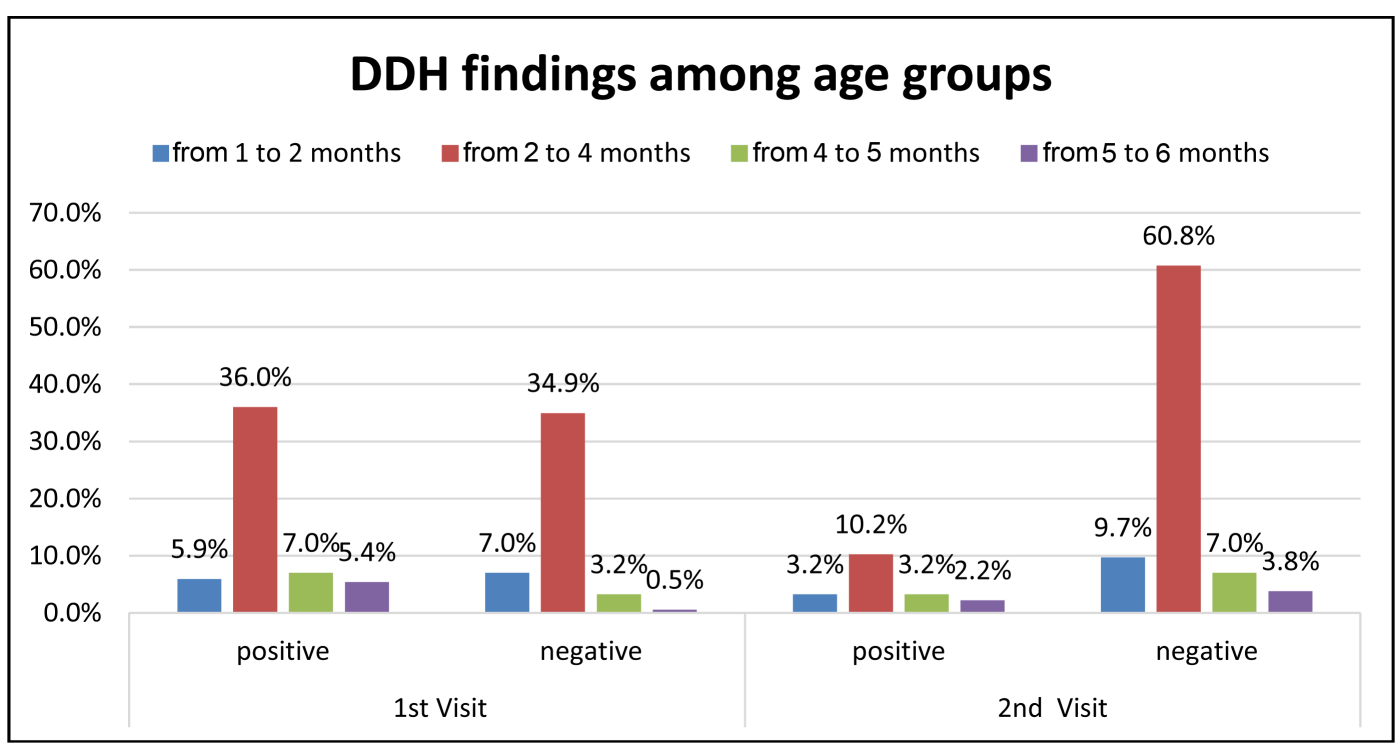

Figure 2. DDH findings on USG matched with age groups.

The number of those with normal stable hips by USG scan (Graf Type I and Type II a+) were 221 (80\%); Female were 155 \& Male 66. While participants in whom abnormal unstable hips considered (Graf Type II a-, II b, II c and Type III a) were $55(20 \%)$ cases. Conservative management (closed reduction) was started (Figure 3).

Out of the 55 with positive findings; the affected hip side which scanned by USG on both sides, right or left; $5(1.8 \%) 7$ (2.5\%) or 43 (15.5\%) consecutively. Unfortunately; only 41 were considered positive based on clinical assessment with findings include hip click, subluxation, limited abduction or unstable hips. 87 of those referred patients labeled by clinical exam as DDH cases, while only 46 of them show negative USG findings for DDH (Figures 4-9).

For those who showed abnormal hip based on USG scan; 3 were referred to the tertiary center for further surgical management. The main clinical findings found among participants with the positive USG were clicking hip and limitation of abduction and/or positive family history as risk factors (Table 4 and $\mathrm{Ta}$ ble 5).

\section{Discussion}

In the current study, 276 infants were screened for DDH by USG at King Khaled 

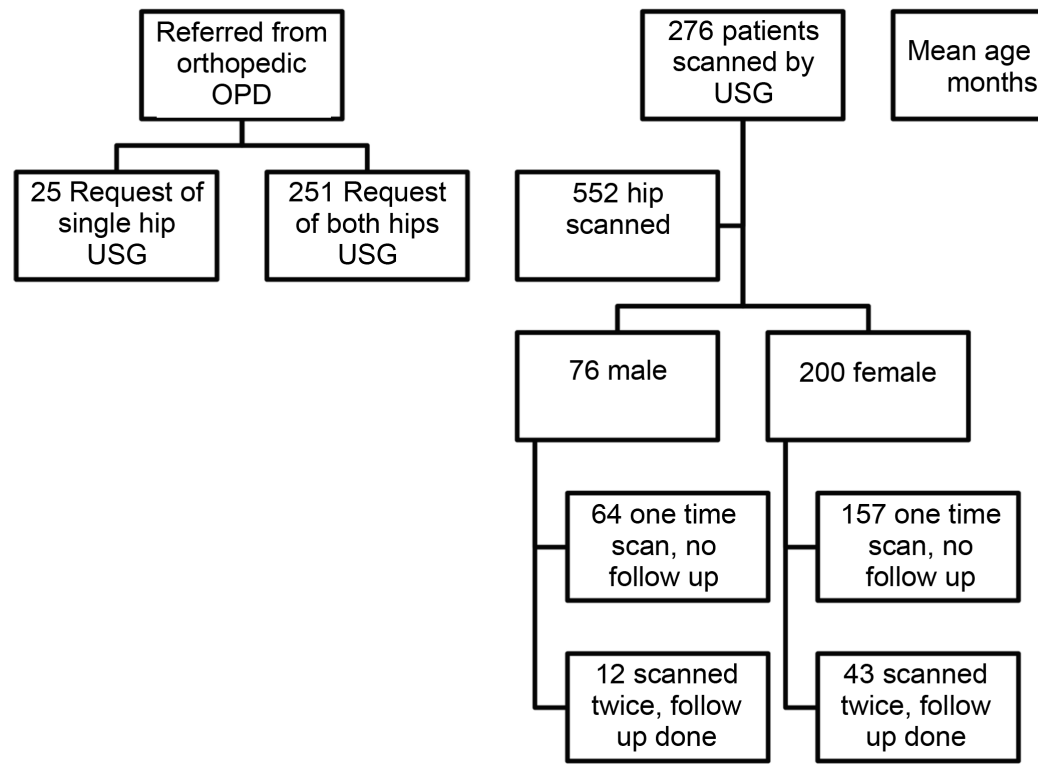

Figure 3. Schematic representation of the results.

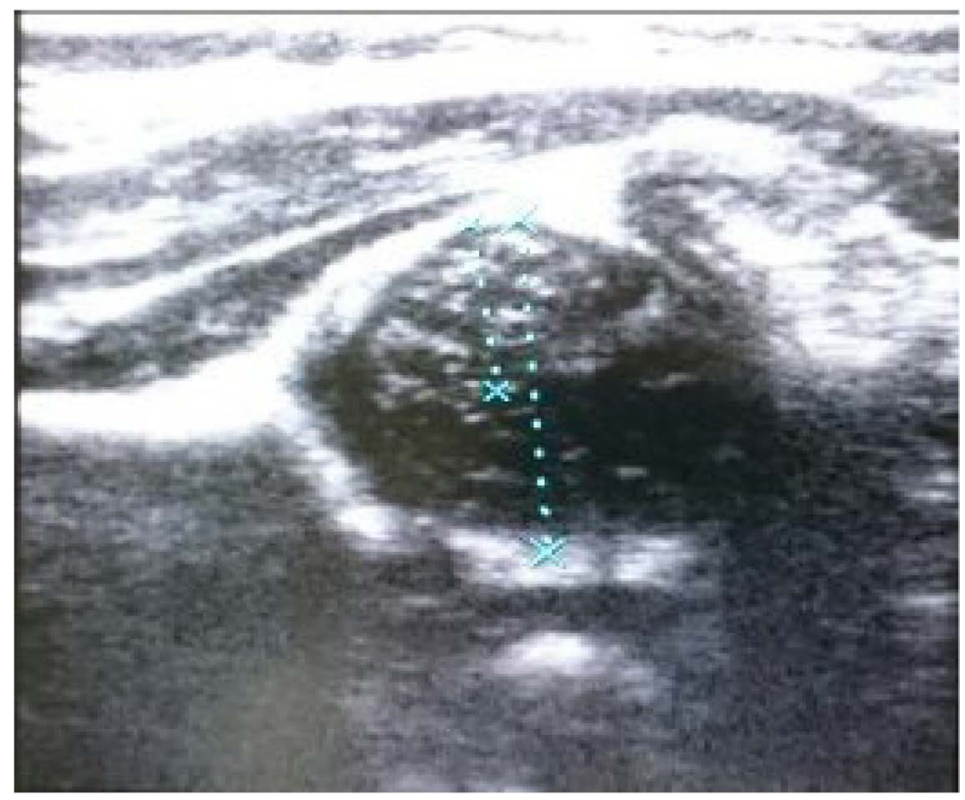

Figure 4. Normal sonogram of the hip with physiological immaturity; Good cupping of the acetabulum, covering \& good femoral head sphericity. However, proximal epiphyseal femoral ossific center is not visualized yet. (Copyright reserved for King Khalid Hospital, Alkharj, SA).

Hospital, which is a governmental hospital to serve as a referral hospital in Al-Kharj region. Female gender was associated with a high percentage of DDH as compared to male infants. For many years, earlier detection of DDH in most parts of the world was based on the Ortolani [10] and Barlow [11] maneuvers. However, in recent years, numerous publications have highlighted the shortcomings of this approach, which is merely subjective findings rather than depending on the detailed morphological evaluation of the anatomopathological substrate underlying the disorder [12] [13]. 


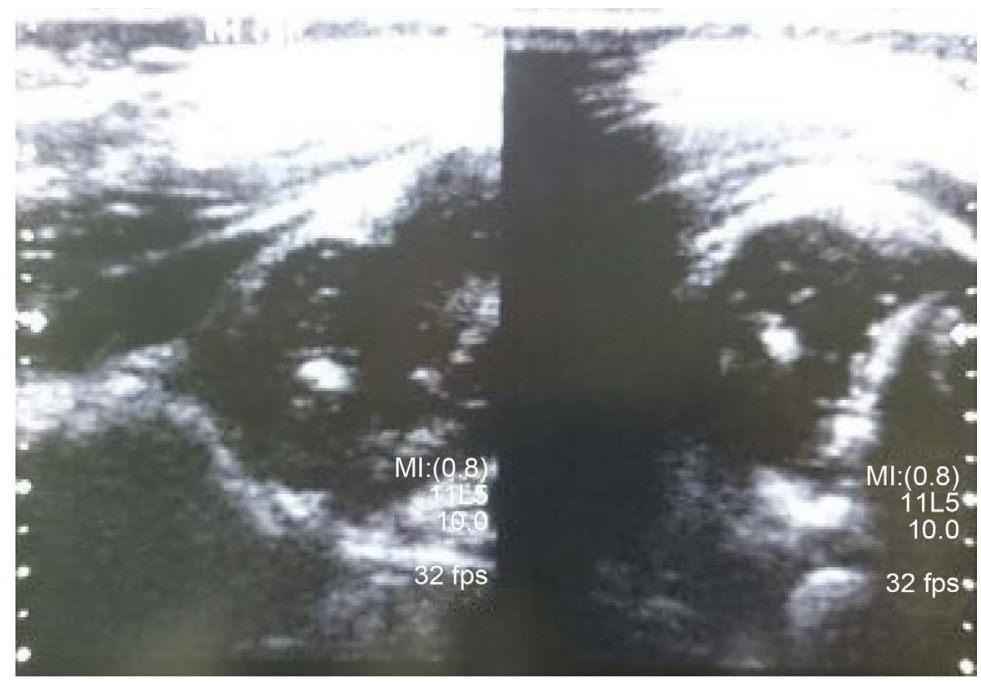

Figure 5. Normal hip joint; Shows deep acetabulum with more than 50\% femoral head coverage. Sphericity and femoral head ossific center are noted. (Copyright reserved for King Khalid Hospital, Alkharj, SA).

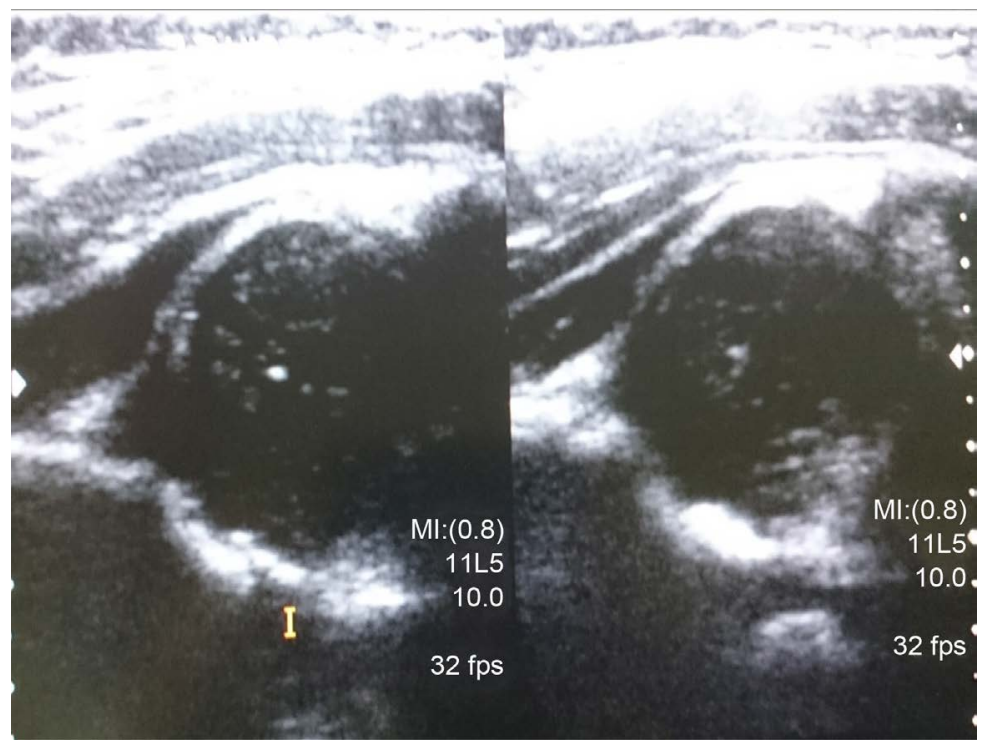

Figure 6. Dysplastic hip joint; Shows shallow acetabulum, lack of femoral head sphericity and delayed or small femoral head ossific center. (Copyright reserved for King Khalid Hospital, Alkharj, SA).

Using USG in the detection of abnormal hip findings was showing the more accurate mean of revealing findings than physical examination with or without presence of risk factors alone. Although, most newborn screening studies suggest that some degree of hip instability can be detected in one in 100 to one in 250 babies, actual dislocated or dislocatable hips are much less frequent being founded in $1-1.5$ of 1000 live births [16]. Unlike the clinical examination signs which was conducted in this study; using Graf's criteria of ultrasonography to assess hip dislocation or instability was showing minimal anatomic abnormalities detected early, most of which will not affect the later development of the hip which will go on to become normal [17]. 


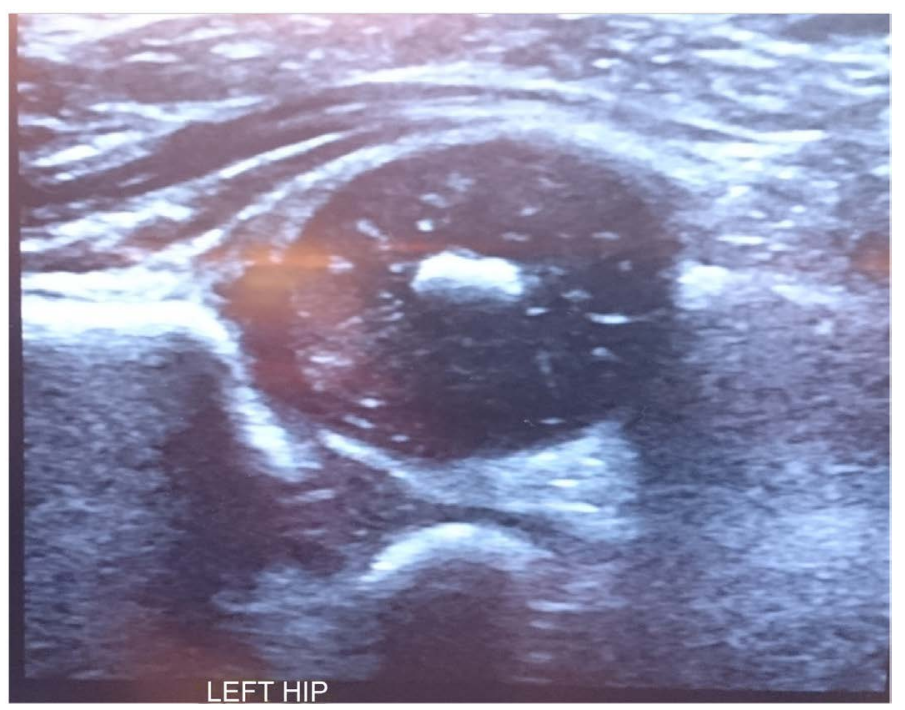

Figure 7. Normal hip; No signs of DDH (Copyright reserved for King Khalid Hospital, Alkharj, SA).

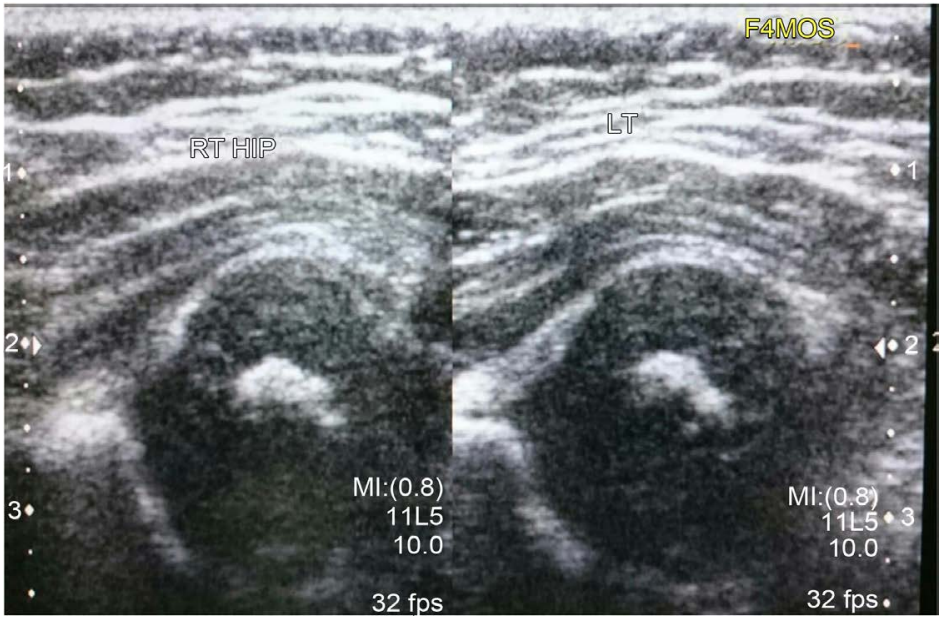

Figure 8. Both sides are normal. (Copyright reserved for King Khalid Hospital, Alkharj, SA).

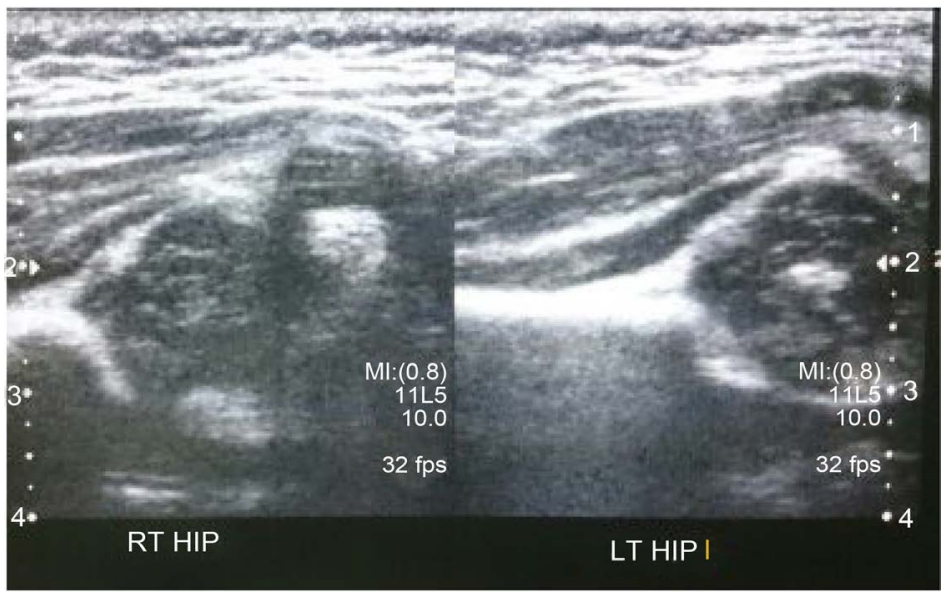

Figure 9. Difference between normal (LT HIP) and dysplastic (RT HIP). (Copyright reserved for King Khalid Hospital, Alkharj, SA). 
Table 4. Sonographic findings, according to Graf's classification and treatment rate per hip type.

\begin{tabular}{cccc}
\hline Sonographic Hip Type & Results $\mathbf{N}=\mathbf{2 7 6}$ & Percentage & Management \\
\hline I (normal) & 196 & $71.01 \%$ & No treatment \\
IIa/IIa+ (immature) & 25 & $9.06 \%$ & Follow up \\
IIa2 (immature) & 37 & $13.41 \%$ & Follow up \\
IIb (abnormal) & 6 & $2.17 \%$ & Conservative \\
IIc (abnormal) & 9 & $3.26 \%$ & Conservative \\
D (abnormal) & 2 & $0.72 \%$ & Surgical \\
III (abnormal) & 1 & $0.36 \%$ & Surgical \\
IV (abnormal) & - & - & - \\
\hline
\end{tabular}

*According to mostly affected hip.

Table 5. Number of patients with positive findings for DDH in examination \& USG use.

\begin{tabular}{ccccc}
\hline & Physical examination $^{*}$ & USG (positive\#) & USG (negative) & Total \\
\hline Male & 16 & 21 & 55 & 76 \\
Female & 25 & 34 & 166 & 200 \\
Total & 41 & 55 & 221 & 276 \\
\hline
\end{tabular}

*Infants with positive findings for DDH. \#Infants with positive findings for DDH.

In the current study; Graf's criteria of ultrasonographic findings were used to assess the relationship between the femoral head and acetabulum \& also used to classify different stages of DDH. It is a standardized quantitative method which is widely used to detect DDH using the USG [18] [19] [20].

The findings of the current survey revealed the accuracy of the hip USG in the detection of DDH. Our data showed the prevalence of DDH among infants with abnormal hip based on the USG was approximately $20 \%$. It was clearly revealed by some studies that most of the hips screened by USG had already diagnosed as negative for DDH using clinical examination alone. In addition, Koşar \& colleagues reported that the selective screening protocol would have missed up to a third of DDH cases [21]. In conclusion, the current study recommends for USG screening of infants regardless of their clinical examination, especially female gender or those with risk factors.

\section{Conclusion}

In conclusion, delayed treatment rates of DDH and complications are minimized by the usage of the USG among infants after the first month. The usage of USG for high-risk infants will give more chance of early diagnosis, manage and hence minimize the future complications.

\section{Limitation of the Study}

Relatively small sample size to generalize the results so we may need larger sam- 
ple size. The study was conducted at one center, so we may need multicenter study.

There is need to conduct a larger multicenter study to discover the factors that highly increased the chance of deformities among newborns with DDH that are not identified by clinical exam only. Also, it is important to provide and train on the use of portable bedside USG in the clinic to evaluate infants that may be missed when using clinical judgment alone.

\section{Acknowledgements}

This project was supported by King Abdul Aziz City for Science and Technology in KSA. We are thankful to the public administration of grant programs for this support.

\section{References}

[1] Harding, M.G., Harcke, H.T., Bowen, J.R., Guille, J.T. and Glutting, J. (1997) Management of Dislocated Hips with Pavlik Harness Treatment and Ultrasound Monitoring. Journal of Pediatric Orthopaedics, 17, 189-198.

https://doi.org/10.1097/00004694-199703000-00010

[2] Dezateux, C. and Rosendahl, K. (2007) Developmental Dysplasia of the Hip. Lancet, 369, 1541-1552. https://doi.org/10.1016/S0140-6736(07)60710-7

[3] Schwend, R.M., Schoenecker, P., Richards, B.S., Flynn, J.M. and Vitale, M. (2007) Screening the Newborn for Developmental Dysplasia of the Hip: Now What Do We Do? Journal of Pediatric Orthopaedics, 27, 607-610. https://doi.org/10.1097/BPO.0b013e318142551e

[4] Graf, R. (1984) Fundamentals of Sonographic Diagnosis of Infant Hip Dysplasia. Journal of Pediatric Orthopaedics, 4, 735-740. https://doi.org/10.1097/01241398-198411000-00015

[5] Clarke, N.M., Clegg, J. and Al-Chalabi, A.N. (1989) Ultrasound Screening of Hips at Risk for CDH: Failure to Reduce the Incidence of Late Cases. Journal of Bone and Joint Surgery, 71, 9-12.

[6] Woolacott, N.F., Puhan, M.A., Steurer, J. and Kleijnen, J. (2005) Ultrasonography in Screening for Developmental Dysplasia of the Hip in Newborns: A Systematic Review. $B M J$, 330, 1413. https://doi.org/10.1136/bmj.38450.646088.E0

[7] Uzel, M., Ergun, G.U. and Ekerbicer, H.C. (2007) The Knowledge and Attitudes of the Primary Care Physicians on Developmental Dysplasia of the Hip. Saudi Medical Journal, 28, 1430-1434.

[8] Jones, D.A. and Powell, N. (1990) Ultrasound and Neonatal Hip Screening. A Prospective Study of "High Risk" Babies. Bone \& Joint Journal, 72, 457-459.

[9] Dezateux, C. and Rosendahl, K. (2007) Developmental Dysplasia of the Hip. Lancet, 369, 1541-1552. https://doi.org/10.1016/S0140-6736(07)60710-7

[10] American Academy of Pediatrics (2000) Committee on Quality Improvement, Subcommittee on Developmental Dysplasia of the Hip. Clinical Practice Guideline: Early Detection of Developmental Dysplasia of the Hip. Pediatrics, 105, 896-905.

[11] Tréguier, C., et al. (2013) Pubo-Femoral Distance: An Easy Sonographic Screening Test to Avoid Late Diagnosis of Developmental Dysplasia of the Hip. European Radiology, 23, 836-844. https://doi.org/10.1007/s00330-012-2635-7

[12] Dornacher, D., Cakir, B., Reichel, H. and Nelitz, M. (2010) Early Radiological Out- 
come of Ultrasound Monitoring in Infants with Developmental Dysplasia of the Hips. Journal of Pediatric Orthopaedics B, 19, 27-31. https://doi.org/10.1097/BPB.0b013e328330335e

[13] Pashapour, N. and Golmahammadlou, S. (2007) Study on the Diagnosis Time of Developmental Dysplasia of the Hip. Eastern Mediterranean Health Journal, 13, 465-469.

[14] Misanovic, V., Jonuzi, F., Maksic-Kovacevic, H. and Rahmanovic, S. (2015) Ultrasound in Detection of Developmental Hip Dysplasia in Premature Born Children. Acta Informatica Medica, 23, 73-75. https://doi.org/10.5455/aim.2015.23.73-75

[15] Orak, M.M., Onay, T., Çağırmaz, T., Elibol, C., Elibol, F.D. and Centel, T. (2015) The Reliability of Ultrasonography in Developmental Dysplasia of the Hip: How Reliable Is It in Different Hands? Indian Journal of Orthopaedics, 49, 610-614. https://doi.org/10.4103/0019-5413.168753

[16] Ortolani, M. (1937) Un segno poco noto e la sua importanza per la diagnosi precoce di pre lUSGsazione congenita dell'anca. Pediatria, 45, 129-136.

[17] Barlow, T.G. (1962) Early Diagnosis and Treatment of Congenital Dislocation of the Hip. Journal of Bone and Joint Surgery, 44, 292-301.

[18] De Pellegrin, M. (1991) Ultrasound Screening for Congenital Dislocation of the Hip. Results and Correlations between Clinical and Ultrasound Findings. Italian Journal of Orthopaedics and Traumatology, 17, 547-553.

[19] Tonnis, D., Storch, K. and Ulbrich, H. (1990) Results of Newborn Screening for $\mathrm{CDH}$ with and without Sonography and Correlation of Risk Factors. Journal of Pediatric Orthopaedics, 10, 145-152. https://doi.org/10.1097/01241398-199003000-00001

[20] Hosalkar, H.S., Horn, D., Friedman, J.E. and Dormans, J.P. (2004) Developmental Dysplasia of the Hip. In: Behrman, R., Kliegman, R.M. and Jenson, H.B., Eds., Nelson's Textbook of Pediatrics, 17th Edition, Saunders, Philadelphia, 2800-2805.

[21] Peled, E., Eidelman, M., Katzman, A. and Bialik, V. (2008) Neonatal Incidence of Hip Dysplasia: Ten Years of Experience. Clinical Orthopaedics and Related Research, 466, 771-775. https://doi.org/10.1007/s11999-008-0132-8

\section{Submit or recommend next manuscript to SCIRP and we will provide best service for you:}

Accepting pre-submission inquiries through Email, Facebook, LinkedIn, Twitter, etc. A wide selection of journals (inclusive of 9 subjects, more than 200 journals) Providing 24-hour high-quality service User-friendly online submission system Fair and swift peer-review system Efficient typesetting and proofreading procedure Display of the result of downloads and visits, as well as the number of cited articles Maximum dissemination of your research work

Submit your manuscript at: http://papersubmission.scirp.org/ Or contact ojped@scirp.org 